\title{
PASSA E FICA A DOR: RESENHA DO LIVRO “UPP A REDUÇÃO DA FAVELA A TRÊS LETRAS” DE MARIELLE FRANCO
}

\section{Fernando de Sá Moreira* \\ Erick Santana**}

Resenha de FRANCO, Marielle. UPP A redução da favela a três letras: uma análise da política de segurança pública do estado do Rio de Janeiro. São Paulo: n-1 edições, 2018.

Em 29 de setembro de 2014, Marielle Franco defendia sua dissertação de mestrado junto ao Programa de PósGraduação em Administração da Universidade Federal Fluminense; no início de 2017, tomava posse como vereadora no município do Rio de Janeiro, após obter 46.502 votos nas eleições do ano anterior; no dia 14 de março de 2018, ela e seu motorista, Anderson Gomes, foram executados em uma emboscada. Os indícios apontam que os executores são ligados às chamadas "milícias", isto é, grupos do crime organizado formados principalmente por agentes e ex-agentes do Estado, normalmente ligados ao ramo da segurança pública e que exploram diversas atividades criminosas, em especial nas comunidades carentes e favelas.

Marielle Franco foi uma mulher, negra, mãe, bissexual, nascida e criada na

\footnotetext{
* Professor Adjunto do Departamento de Fundamentos Pedagógicos da UFF, doutor em Filosofia pela PUCPR. ORCID ID: https://orcid.org/0000-00029545-435X. E-mail: fernandosm@id.uff.br.

${ }^{*}$ Professor da Educação Infantil na escola Jardim de Infância Primavera, formado pelo Curso Normal no Instituto de Educação Professor Cláudio Gama, graduando em Pedagogia da UFF.

E-mail: erickredacao@gmail.com
}

favela da Maré. Por meio da educação, alcançou espaços frequentemente interditados a indivíduos com marcas $e$ origens como as suas. Formou-se cientista social e obteve o título de mestra em administração. Como vereadora, militou em prol de melhores condições de vida aos que sobrevivem (e sobreviveram) aos diversos sistemas de violência e opressão; uma realidade que ela mesma conhecia muito de perto.

Desde o dia 14 de março de 2018, o nome de Marielle Franco tem sido entoado com mais intensidade. O crime político que a executou revela o quão frágil e injusta é a democracia brasileira. Ademais, vale ressaltar que, ainda que tenha sido um atentado político, Marielle pertencia a grupos sociais que estão entre os mais expostos à violação de direitos, à violência e à morte. ${ }^{3}$

${ }^{3} \mathrm{E}$ o caso de se observar, por exemplo, o que acontece com a população negra no Brasil. Abdias do Nascimento afirmava que o racismo mascarado que vivemos é o promotor de um verdadeiro genocídio (NASCIMENTO, 2017). Os dados do Atlas da Violência, organizado pelo Instituto de Pesquisa Econômica e Aplicada (IPEA), órgão do Governo Federal fortalecem essa tese. Desde 2005 a taxa de homicídios de pessoas negras no Brasil tem aumentado sensivelmente. O número saltou de 31,3 homicídios a cada 100 mil habitantes em 2005 para

MOREIRA, Fernando de Sá; SANTANA, Erick. Passa e fica a dor: resenha do livro "UPP a redução da favela a três letras" de Marielle Franco. Revista Sul-Americana de Filosofia e Educação. Número 32/33: nov. 2019 - out. 2020, p. 206-213. DOI: https://doi.org/10.26512/resafe.v1i32/33.35123 
Contudo, em meio à desesperança, o luto foi transformado em luta. Palavras de ordem como "Marielle, vive!" e "Marielle, presente!" ratificam que a tentativa de calar uma vereadora eleita fracassou, apesar da proliferação de informações falsas $e$ difamatórias surgidas após sua morte. ${ }^{4}$ Marielle tornou-se semente, e as pautas que ela carregava foram amplificadas, nacional $e$ internacionalmente.

Esse cenário tem, sem dúvida, um caráter trágico. As lutas de Marielle Franco, sua vida e também sua morte colocam em destaque as graves falhas no atendimento às demandas sociais e da segurança pública em nosso país, em especial no Estado do Rio de Janeiro. É precisamente sobre essa difícil interseção entre as políticas de segurança pública e a vida das populações marginalizadas que se debruça sua dissertação de mestrado, sob o título de "UPP - a redução da favela a três letras: uma análise da política de segurança pública no estado do Rio de Janeiro". Como sugere o título, a autora analisa, questiona e critica a política de segurança pública das "Unidades de Polícia Pacificadora" no Rio de Janeiro entre 2008 e 2014. À época, essa política prometia promover uma verdadeira

40,2 em 2016. A diferença em comparação com as taxas relativas à população não negra é enorme: além de serem apresentarem números menores, a taxa de homicídios de não negros caiu no mesmo período, passando de 17,1 a cada 100 mil habitantes em 2005 para 16 no ano de 2016.

${ }^{4}$ Nos meses seguintes à execução de Marielle Franco e Anderson Gomes, a equipe que mantém seu site oficial chegou a criar uma seção especial para combater as principais informações falsas veiculadas nas redes sociais (https://www.mariellefranco.com.br/averdade, acesso em 22 de março de 2019). revolução na relação entre a polícia $e$ as favelas cariocas.

A presente resenha refere-se ao livro no qual a dissertação de Marielle Franco foi transformada, lançado postumamente alguns meses após sua execução. Nosso interesse nesta resenha não é apenas discorrer sobre o livro em si, mas também refletir brevemente sobre algumas relações possíveis que $\mathrm{o}$ trabalho da autora tem com o tema da educação.

Quando se toma esse material em mãos, a primeira coisa a se notar é que há um forte diálogo entre o tema da dissertação e o projeto gráfico do livro. A imagem da capa é de um azul soturno e retrata a vista de diversas áreas nobres e conhecidas da cidade do Rio de Janeiro. Identificam-se facilmente, por exemplo, a silhueta da estátua do Cristo Redentor no Corcovado, a Lagoa Rodrigo de Freitas, a orla dos bairros de Ipanema e Leblon. Aparentemente, a foto foi batida do Mirante Dona Marta e, embora invisíveis na paisagem, vale lembrar que nessa mesma região se localizam diversos territórios marginalizados. Podemos mencionar, por exemplo, a Favela Santa Marta, no Morro Dona Marta, onde foi implantada a primeira UPP; as Favelas do Vidigal e da Rocinha, separadas pelo Morro Dois Irmãos; e o Quilombo do Sacomã, na encosta do Morro dos Cabritos.

A primeira página do livro é completamente preta, exceto pelas palavras de ordem "MARIELLE, PRESENTE". E, nas partes internas da primeira e da última capa se encontra uma foto de uma favela sob um céu noturno. $\mathrm{O}$ tom predominante, em evidente contraste com a capa, é alaranjado. Olhar essa fotografia com o livro aberto 
parece ampliar o significado da primeira página. Ali, onde lemos "Marielle, Presente", poderíamos talvez também ler "Favela, Presente". A imagem distante e fria da capa contrata diretamente com a proximidade e o calor do interior do livro. Esse olhar sobre a favela convida o leitor a um distanciamento da imagem desses territórios como sombrios, violentos e, acima de tudo, como territórios da criminalidade.

Parte do trabalho da autora diz respeito justamente a combater os estigmas sociais que recaem sobre as favelas:

Há duas ações predominantes no Estado frente aos territórios populares: tornar-se ausente, ou não se fazer totalmente presente. As duas opções demonstram a escolha feita pelo Estado, seja quando sob a prerrogativa da garantia de direitos, opta por baixos investimentos $e$ poucos equipamentos e/ou marca a sua presença com o uso da força $e$ da repressão, principalmente por meio da ação policial. Reforça-se, assim, a visão predominante de que favelas e periferias são locais de ausência, carência, onde predomina a 'vagabundagem', ou então, usa-se a narrativa do assistencialismo, em um espaço considerado território de "pobres coitados". Por outro lado, também pretendemos fazer uma reflexão que reforce a ideia de favelas e periferias como locais de produção, melhor dizendo, de potência, onde seus moradores, mesmo diante da realidade de baixos investimentos pelo Estado, inventaram suas diversas formas de regular e de resistir à vida: por meio das artes, moradias, mobilidades, encontros etc. (p. 25s.)

O objeto de pesquisa da autora, a política das UPPs, foi apresentadas pelo Estado do Rio de Janeiro em sua implantação em 2008 e nos anos subsequentes como uma proposta de revolução na segurança pública do estado. Essa política supostamente instalaria uma nova forma de presença policial e estatal nos territórios das favelas ocupadas pelo crime organizado, em especial pelo varejo do tráfico de drogas. Tradicionalmente, os territórios dominados pelo crime organizado possuem pouca presença do Estado e das forças de segurança. A atuação policial ocorre principalmente na forma de operações pontuais de cunho repressivo, nas quais as unidades policiais adentram a favela, realizam uma série de ações de controle e apreensão, para logo em seguida abandonar novamente o território.

Com a instalação de uma UPP em uma favela, a presença policial passaria a ser constante, mas agora não apenas através de operações de enfrentamento, apreensão ou repressão, mas também por meio de estratégias de uma "polícia de proximidade" ou, ainda, de uma "polícia comunitária". Além disso, a presença constante de policiamento naquele território deveria igualmente garantir a instalação $e$ manutenção de serviços privados, públicos e comunitários anteriormente ausentes ou de funcionamento deficiente. Em outras palavras, as UPPs deveriam servir como um suporte para garantir o exercício pleno da cidadania pelas populações dos espaços marginalizados da cidade, ${ }^{5}$ inclusive através de ações de melhoramento da qualidade da

\footnotetext{
${ }^{5}$ Faz-se necessário observar que, muito embora seja um programa estadual, as UPPs se concentraram quase exclusivamente no município do Rio de Janeiro.
} 
educação nas favelas e para a população periférica como um todo.

A perspectiva defendida pela autora em sua dissertação de 2014, no entanto, foi de que, até então, 6 anos após a implantação da primeira UPP, essa política não cumpria sua promessa de revolucionar a lógica vigente da segurança pública $e$ principalmente da política e da economia das cidades, nem teria sido projetada de fato com esse objetivo. Embora trouxesse mudanças na organização e ação policial nas favelas cariocas, a política das UPPs poderia ser melhor descrita como um mero desdobramento da lógica vigente das polícias, da política e dos interesses econômicos em curso:

Buscamos, ainda, apontar que a administração da segurança não contribuiu com qualquer alteração qualitativa. Ao contrário, atuou como força auxiliar no fortalecimento de um modelo de cidade centrado no lucro privado, $e$ não na sua população, sustentado pela política hegemônica do Estado, marcada pela exclusão e punição. (p. 20s.)

Diversas razões levam a autora a defender essa tese. Dentre seus argumentos, gostaríamos de destacar alguns dos mais marcantes.

Segundo a perspectiva defendida pela autora, a presença mais ostensiva das forças de segurança do Estado peca por não superar o imaginário de que as populações marginalizadas são a origem do problema da criminalidade e de que a melhor maneira de combater a criminalidade é essencialmente através de medidas ostensivas e repressivas de confronto armado, controle, apreensão e aprisionamento nos territórios das favelas.
Nesse sentido, sendo o comércio ilegal de drogas percebido como um dos principais fatores de geração de insegurança, uma "guerra às drogas" é vista como o principal instrumento de promoção da segurança pública.

Como o imaginário sobre o território da favela associa injustificadamente seus moradores quase indistintamente à atividade criminosa, a população marginalizada não apenas sofre frequentemente com os danos colaterais dessa suposta "guerra às drogas", como também é vista ela mesma como parte do inimigo a ser eliminado. Não raro, o resultado desse cenário emerge na forma de incontáveis violações aos direitos humanos que atinge uma população que já encontra dificuldade de ver seu direito à cidade e à cidadania respeitado. A "guerra às drogas" se mostra, portanto, como uma "guerra aos pobres", uma guerra que vitima em especial a população negra. A descrição desse cenário nos traz frequentemente reminiscências do conceito de necropolítica de Achille Mbembe (2018), ou seja, de um cenário no qual os arranjos de poder e de exploração se organizam de tal forma, que criam a imagem de que seria tolerável, aceitável ou até mesmo desejável que ocorram violações de direitos e a morte das populações das favelas.

Vale lembrar que as violações de direitos, das quais Marielle Franco fala, afetam até mesmo os policiais que atuam $e$ atuaram nas UPPs. Em seu trabalho, a pesquisadora aponta diversos abusos por parte do próprio Estado no recrutamento, treinamento e alocação dos agentes de segurança nas Unidades de Polícia Pacificadora. Sobre esse ponto, ela diz: "Não 
há como hierarquizar a dor, ou acreditar que apenas será doído para as mães de jovens favelados. O Estado bélico e militarizado é responsável pela dor que paira também sobre as dezesseis famílias dos policiais mortos desde o início das UPPs [até 2014]" (p. 107). Não se trata apenas da violência e da morte de policiais em confrontos com o crime organizado, mas também nas mãos do próprio Estado.

Marielle nos relata (p. 97 s.), por exemplo, o caso da morte do recruta da Polícia Militar Paulo Aparecido Santos de Lima. O recruta - já aprovado na primeira fase das provas teóricas - foi submetido, junto a outros recrutas, a testes que objetivavam avaliar as aptidões físicas dos policiais. Neste dia, em diversos pontos do Rio de Janeiro, a sensação térmica atingiu a marca de $50^{\circ} \mathrm{C}$. Mesmo assim, os testes incluíram intensas atividades sob forte calor. Paulo lamentavelmente morreu por exaustão física em decorrência do treinamento. Em depoimentos ao Ministério Público do Estado, outros recrutas denunciaram outras violações, incluindo queimaduras resultantes do contato com o asfalto excessivamente quente.

A partir desse relato, a autora analisa como o processo de embrutecimento $e$ desumanização faz parte da formação policial e, por esse motivo, questiona: "esses são os mesmo policiais que estão sendo formados para processo de 'pacificação', proximidade e interlocução nas favelas cariocas?" (p. 98).

Quando analisa alguns dos resultados pretensamente positivos da política das UPPs, a pesquisadora constata que "decididamente, o Estado cumpre um papel de agente para o mercado e não agente de cidadania" (p. 46). Isso é evidenciado, por exemplo, pela prioridade no atendimento das demandas do mercado, em detrimento da população da favela "pacificada". O resultado aparece em fatores tais como a valorização dos imóveis localizados próximos às favelas; a expectativa de lucro com a regularização de serviços de água, luz e gás pelas empresas privadas, eventualmente a um preço proibitivo para a parte mais necessitada da população local; o atendimento à demanda de segurança para a realização de grandes eventos como a Copa do Mundo de Futebol em 2014 e as Olimpíadas em 2016, eventos de grande interesse para o mercado; etc.

A implantação das UPPs daria, portanto, uma resposta prioritariamente aos anseios de uma pequena parcela da população, que já se encontra menos exposta à violência e à violação de direitos, $e$ principalmente do mercado, interessado no desenvolvimento da cidade como uma espécie de mercadoria ou de recurso a ser explorado. Ao passo que as demandas da população da favelas são pouco ou não são em absoluto atendidas. E suas iniciativas locais de organização da vida e de reivindicação são eventualmente desmanteladas no processo de instalação da UPP.

Como se pode observar, de acordo com o ponto de vista defendido pela autora, a política das UPPs caracteriza-se como um aprofundamento da lógica de controle das populações dos territórios marginalizados. A UPP emerge fundamentalmente como uma política de segurança e controle público, e não de promoção da cidadania. Na prática, 
as Unidades de Polícia Pacificadora não se apresentaram - ou se apresentaram de forma deficitária - acompanhadas de outras políticas públicas reivindicadas pelas populações marginalizadas, como promoção do trabalho, desenvolvimento de renda, acesso à saúde, à educação, ao lazer etc.

É verdade que alguns anos após o início das operações das UPPs foi também lançado um programa complementar, cujo objetivo era justamente iniciar a implantação de projetos de promoção da cidadania nas favelas "pacificadas". O programa foi inicialmente conhecido como "UPP Social" $e$ era de responsabilidade do governo do estado do Rio de Janeiro. Posteriormente a responsabilidade pelo programa foi transferida para o governo municipal do Rio de Janeiro. ${ }^{6}$ As principais críticas da autora se direcionam à insuficiência do programa $e$ a falta de prioridade que ele recebia, pois a iniciativa de promoção à cidadania (UPP Social) chegava normalmente anos depois da iniciativa de segurança (UPP). É preciso observar também que, até 2014, apenas algumas poucas favelas "pacificadas" receberam ações do programa UPP Social.

Vale a pena destacar ainda o último capítulo da obra, intitulado "A organização popular e as resistências possíveis". Esse capítulo tem a função de justamente

\footnotetext{
${ }^{6}$ Atualmente o programa é conhecido como "Rio mais Social" ou também "Rio + Social". Tudo leva a crer que as mudanças não foram capazes de reverter as limitações do antigo programa "UPP Social". Por exemplo, em maio de 2017, a Agência Lupa publicou uma matéria sobre o programa e constatou que a implantação do programa seguia precária, mesmo 3 anos decorridos das análises de Marielle Franco. O próprio programa das UPPs parece encontrar-se atualmente em desmonte. Com efeito, em abril de 2018, foram anunciados plano para o fechamento de metade das unidades instaladas (LUCCHESE, 2018).
}

apresentar as favelas como territórios de resistência e de agência. A seu ver, o papel do Estado e das polícias não é o de pensar e aplicar políticas públicas nas favelas partindo fundamentalmente de uma visão exterior da favela. Ao contrário, trata-se de reconhecer a favela como um território vivo e, portanto, permeada de iniciativas e propostas de solução de suas demandas que precisam ser devidamente observadas e ouvidas. A autora cita diversos exemplos de iniciativas cidadãs e também de enfrentamento à violência surgidas nas favelas cariocas, que vão de cartilhas informativas sobre direitos civis a blocos carnavalescos com propósitos políticos, culturais e educacionais.

Especificamente sobre o tema educação é o caso de dedicar ainda algumas palavras. Marielle Franco não era uma especialista da área de Educação. Porém, isso não significa que seu livro não deva ser também do interesse dos profissionais $e$ pesquisadores da área. O livro ora resenhado é um território fértil para pensar de forma interdisciplinar as questões contemporâneas da educação. Podemos citar como exemplos a relação entre a educação como política pública com outras políticas públicas, em especial a segurança pública; também é possível refletir a partir de Marielle Franco a educação e sua relação com o treinamento dos agentes de segurança do Estado, que deveria ser, afinal, também um ato educativo; pode-se pensar também sobre o lugar e a finalidade da educação em uma cidade pensada como mercadoria, sob um Estado promotor dos interesses de certas classe e grupos sociais e econômicos em detrimento de outros; etc. 
Além das potencialidades intrínsecas à dissertação da autora, é importante igualmente ressaltar que também é possível analisar e debater seu envolvimento com o tema da educação a partir de sua atuação política. Um elemento que parece ser proveitoso aqui é, por exemplo, sua campanha em 2016 para o cargo de vereadora do município do Rio de Janeiro, cuja pauta central girava em torno do debate sobre os eixos das questões de gênero, raça e classe social (com especial olhar para os moradores das favelas cariocas). Porém sua campanha nunca deixou de se relacionar fortemente com o tema da educação, tanto do ponto de vista teórico, ao debater as demandas e intersecções entre os três eixos, quanto do ponto de vista prático, ao preocupar-se em proporcionar espaços recreativo-educativos para crianças em suas ações de campanha, para que fosse possível garantir a efetiva participação política de cuidadores nas ações de campanha, em especial as mães de classes populares. ${ }^{7}$

O debate sobre a educação com $e$ através de Marielle Franco é fundamentalmente um debate interseccional e político, mas poderíamos dizer em certo sentido que é também educacional. Como todo debate verdadeiro, ele envolve atos de fala, mas também de escuta dos sujeitos concretos, cuja vida não pode ser reduzida a política de

${ }^{7}$ No dia 13 de março de 2019, o PCESP Podcast lançou um episódio sobre Marielle Franco com um olhar especial para o tema da educação em sua campanha eleitoral em 2016 e também sua atuação como vereadora do Rio de Janeiro entre 2017 e 2018. Participaram do programa educadoras diretamente envolvidas com o tema da educação em sua campanha e em seu mandato. controle e submissão; assim como também não o pode nenhuma educação verdadeira. 


\section{Referências}

FRANCO, Marielle. UPP - A redução da favela a três letras: uma análise da política de segurança pública do Estado do Rio de Janeiro. Dissertação (Mestrado em Administração) Universidade Federal Fluminense. Niterói, 2014. Disponível em: <https://app.uff.br/riuff/bitstream/1/2166/1/Marielle\%20Franco.pdf >. Acesso em 21/02/2019.

IPEA. Atlas da violência 2018. Disponível em <http://www.ipea.gov.br/atlasviolencia/download/9/atlas-2018>. Acesso em 04/04/2019.

LUCCHESE, Bette. Gabinete de Intervenção no RJ decide acabar com metade das UPPs. Matéria publicada em 26/04/2018. Disponível em <https://g1.globo.com/rj/rio-dejaneiro/noticia/gabinete-de-intervencao-no-rj-decide-acabar-com-metade-das-upps.ghtml> . Acesso em 05 de abril de 2019.

LUPA. Quem se lembra da UPP Social? Disponível em $<$ https://piaui.folha.uol.com.br/lupa/2017/05/10/quem-se-lembra-da-upp-social/>. Acesso em 05 de abril de 2019.

Marielle Franco. Disponível em <www.mariellefranco.com.br>. Acesso em 22 de março de 2019.

MBEMBE, Achille. Necropolítica: biopoder, soberania, estado de exceção, política de morte. Traduzido por Renata Santini. São Paulo: n-1 edições, 2018.

NASCIMENTO, Abdias. O genocídio do negro brasileiro: processo de um racismo mascarado. 1. reimpressão da 2. edição. São Paulo: Perspectiva, 2017.

PCESP Podcast \#15 Marielle. Disponível em <https://profscontraoesp.org/2019/03/13/pcesppodcast-15-marielle/>. Acesso em 05/04/2019.

Recebido em: 01/12/2019 Aprovado em: 17/08/2019 